\title{
PhiC31 recombination system demonstrates heritable germinal transmission of site-specific excision from the Arabidopsis genome
}

\author{
James G Thomson ${ }^{1 *}$, Ronald Chan¹, Roger Thilmony', Yuan-Yeu Yau², David W Ow ${ }^{2,3}$
}

\begin{abstract}
Background: The large serine recombinase phiC31 from broad host range Streptomyces temperate phage, catalyzes the site-specific recombination of two recognition sites that differ in sequence, typically known as attachment sites attB and attP. Previously, we characterized the phiC31 catalytic activity and modes of action in the fission yeast Schizosaccharomyces pombe.

Results: In this work, the phiC31 recombinase gene was placed under the control of the Arabidopsis OXS3 promoter and introduced into Arabidopsis harboring a chromosomally integrated attB and attP-flanked target sequence. The phiC31 recombinase excised the attB and attP-flanked DNA, and the excision event was detected in subsequent generations in the absence of the phic31 gene, indicating germinal transmission was possible. We further verified that the genomic excision was conservative and that introduction of a functional recombinase can be achieved through secondary transformation as well as manual crossing.

Conclusion: The phiC31 system performs site-specific recombination in germinal tissue, a prerequisite for generating stable lines with unwanted DNA removed. The precise site-specific deletion by phiC31 in planta demonstrates that the recombinase can be used to remove selectable markers or other introduced transgenes that are no longer desired and therefore can be a useful tool for genome engineering in plants.
\end{abstract}

\section{Background}

Plant biotechnology has a role in addressing global needs for food, fiber and fuel, by developing new crop varieties with increased pest resistance, biofortification, and abiotic stress tolerance. Publicly acceptable forms of biotechnology offer an avenue for meeting these demands [1]. Recombinase-mediated genetic engineering provides a favorable direction for enhancing the precision of biotechnological approaches. Concerns over the presence of antibiotic resistance genes in the food supply and their escape into the environment [2] can be relieved through the use of recombinase technology to excise unwanted DNA from the genome of genetically engineered (GE) crops prior to marketing or release [3,4]. A study by Chawla and colleagues [5] documented how site-specific integration in rice exhibited stable gene expression over multiple generations. The research

\footnotetext{
* Correspondence: James.Thomson@ars.usda.gov

${ }^{1}$ Crop Improvement and Utilization Research Unit, Western Regional Research Center, USDA-ARS, 800 Buchanan Street, Albany CA, 94710, USA
}

also demonstrated that rice with multicopy transgene inserts, initially silenced for expression, recovered expression when resolved by recombinase technology to a single genomic copy. Such studies demonstrate other potential uses for recombinase technology in the development of plant biotechnology.

Genomic engineering took a large step forward with the discovery that site-specific recombinases, a group of enzymes that are capable of precise DNA cleavage and ligation without the gain or loss of nucleotides, could facilitate conservative DNA manipulation in a heterologous host [6]. The recombinase super family is split into two fundamental groups, the tyrosine and serine enzymes. This grouping is based on the active amino acid ( $\mathrm{Y}$ or $\mathrm{S}$ ) within the catalytic domain of each enzyme family. The best known tyrosine recombinases are Cre, Flp and R [7]. Tyrosine recombinases utilize identical recognition sites and perform a bi-directional mode of recombination. They have been shown to be effective for excision of unwanted DNA from the 
genome of the host but require complex schemes for integration.

The serine enzyme group includes the phiC31, TP9011 and Bxb1 recombinases among others [8,9]. Members of this group recognize two non-identical recognition sites ( $a t t B$ and $a t t P$ ) and perform a uni-directional mode of recombination. While less research has been conducted on this group, it appears that the serine enzymes are well suited for precise genomic recombination due to their uni-directional catalytic activity that prevents the reversion of recombination products.

In previous studies, we identified a number of prokaryotic site-specific recombination systems that function in the eukaryote Schizosaccharomyces pombe $[8,10]$. Among those, the phiC31 uni-directional recombinase was highly efficient. The system has been successfully shown capable of recombinase mediated excision, inversion and integration reactions. The phiC31-att system is derived from the broad host range Streptomyces temperate phage phiC31 [11]. The 613 amino acid phiC31 protein acts on recognition sites $a t t B$ and attP that are minimally $34 \mathrm{bp}$ and $39 \mathrm{bp}$, respectively [12]. Published evidence has demonstrated that the phiC31 system is functional for excision and transmission of marker-free plastids in the seed of tobacco and in the genome of Arabidopsis and wheat [13-17] but has yet to be demonstrated capable of germinal transmission of nuclear DNA in planta.

In this research, we tested the phiC31 recombination system for the capacity to germinally transmit a target sequence that has undergone site-specific excision from within the Arabidopsis genome to a subsequent generation in the absence of the recombinase gene. Plants transgenic for an attB and attP flanked target sequence were introduced with a second construct that contained the recombinase gene. The phiC31 recombinase performed excision of the target sequence from three independent plant lines (i.e. genomic locations) and generated stably excised progeny plants that carry only the recombined target DNA of interest in the absence of the recombinase gene. This demonstrates that the phiC31 recombination system is suitable for the generation of stable marker-free, recombinase-free transgenic plants.

\section{Results}

\section{Experimental design}

To test for site-specific recombination, we initially sought to use a gain-of-function strategy whereby excision of a transgene would lead to promoter fusion with a previously distal marker [18]. Hence, pN3-phiC31 was configured with a CaMV 35S promoter (35S) proximal to a $760 \mathrm{bp}$ non-coding stuffer region followed by a distal gusA coding region (Fig. 1a). The stuffer region is flanked in direct orientation by the 54 bp attB and 57 bp attP phiC31 attachment sites (Fig. 1d) derived from pPB-phiC31 [8] located in the binary vector pCambia 1301 http://www.cambia.org/daisy/cambia. The expectation was that prior to site-specific recombination, $35 \mathrm{~S}$ would not drive expression of gusA due the presence of the stuffer region. After recombination, the non-coding stuffer would be removed and activate expression of gusA (Fig. 1c). In this strategy, we first introduced the recombination target (pN3-phiC31) into the Arabidopsis genome via Agrobacterium transformation. The target construct contains hptII (hygromycin phosphotransferase II) for selection of transgenic plants and was intentionally placed outside of the recombination recognition sites (and thus is not excised by phiC31) to aid the tracking of excised plants. These target lines, or 'TA' lines, were then transformed with the second construct, pCOXS3-phiC31 (Fig. 1b) that expresses the recombinase gene to produce the 'TR' lines. Upon site-specific excision of the recognition site-flanked DNA, the $\mathrm{TR}_{1}$ plants were backcrossed to wild type plants and the $\mathrm{BC}_{1}$ progeny screened for segregants that retain the excision event but lack the recombinase gene (Fig. 2).

\section{Target lines for phic31 recombination}

The target construct pN3-phiC31 was introduced into Arabidopsis and 23 hygromycin resistant lines were confirmed by PCR detection of a $1.26 \mathrm{~kb}$ product that spans the recognition site-flanked non-coding stuffer region (data not shown). Of those, $13 \mathrm{pN} 3$-phiC31 lines were propagated to the $\mathrm{TA}_{2}$ generation and examined by Southern blot for single copy T-DNA integration. EcoRI or BamHI each cuts once within the target TDNA (Fig. 1a). Hybridization with a gusA probe of EcoRI or BamHI cleaved genomic DNA should reveal a band size $>4.17 \mathrm{~kb}$, the length of the cleaved T-DNA. A hybridizing band $<4.17 \mathrm{~kb}$ would indicate integration of a truncated T-DNA. From this analysis, three of the 13 pN3-phiC31 plants were determined to contain a single copy of a likely complete T-DNA (data not shown) and designated $\mathrm{TA}_{2}$-phiC31.22, 31, and 34. The $1.26 \mathrm{~kb}$ PCR product from each of these lines was sequenced to confirm the presence of intact attB and attP sites (Fig. 1d).

\section{Arabidopsis OXS3 promoter for expression of phiC31}

As previous research has demonstrated successful germline tissue expression of the parA and cre recombinase genes [19], we chose the $1.5 \mathrm{~kb}$ promoter fragment of the Arabidopsis Oxidative Stress 3 gene (OXS3) (AGI At5g56550) for phiC31 gene expression and termed the plasmid pCOXS3-phiC31 (Fig. 1b). Independent research, through the use of tiling microarrays, has also confirmed that the OXS3 gene is constitutively expressed in most Arabidopsis tissues [20,21]. 


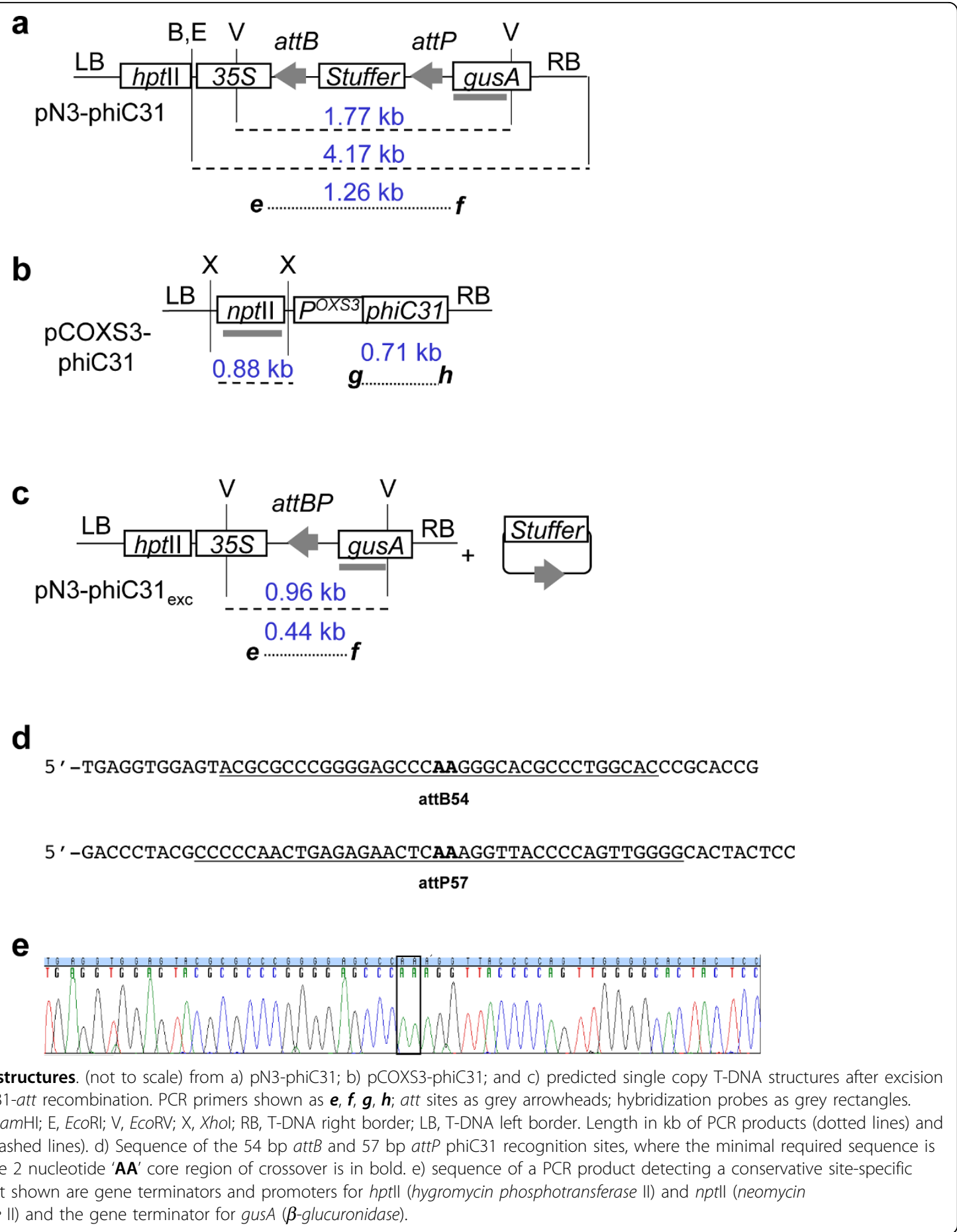

\section{Secondary transformation of TA target lines}

The $\mathrm{TA}_{3}$ generation of phiC31.22, 31, 34 plant lines were transformed with Agrobacterium harboring the pCOXS3-phiC31 vector. Kanamycin resistant transformants that exhibited wild type appearance and growth rate were identified and grown in the greenhouse. Three-week old $\mathrm{TR}_{1}$ transformants were tested for the presence of the phiC31 gene. PCR amplification by primers $\boldsymbol{g}$ and $\boldsymbol{h}$ (Fig. 1b) showed that a majority of the plants harbor the recombinase gene (Fig. 3). The groups of plants that harbor the phiC31 gene were designated $\mathrm{TR}_{1}$-phiC31.22, 31 and 34 (Table 1).

The $\mathrm{TR}_{1}$-phiC31 lines were examined using histochemical staining to detect gus $A$ encoded $\beta$-glucuronidase activity. GUS expression in the $\mathrm{TR}_{1}$-phiC31 lines, however, showed variable levels of $\beta$-glucuronidase 


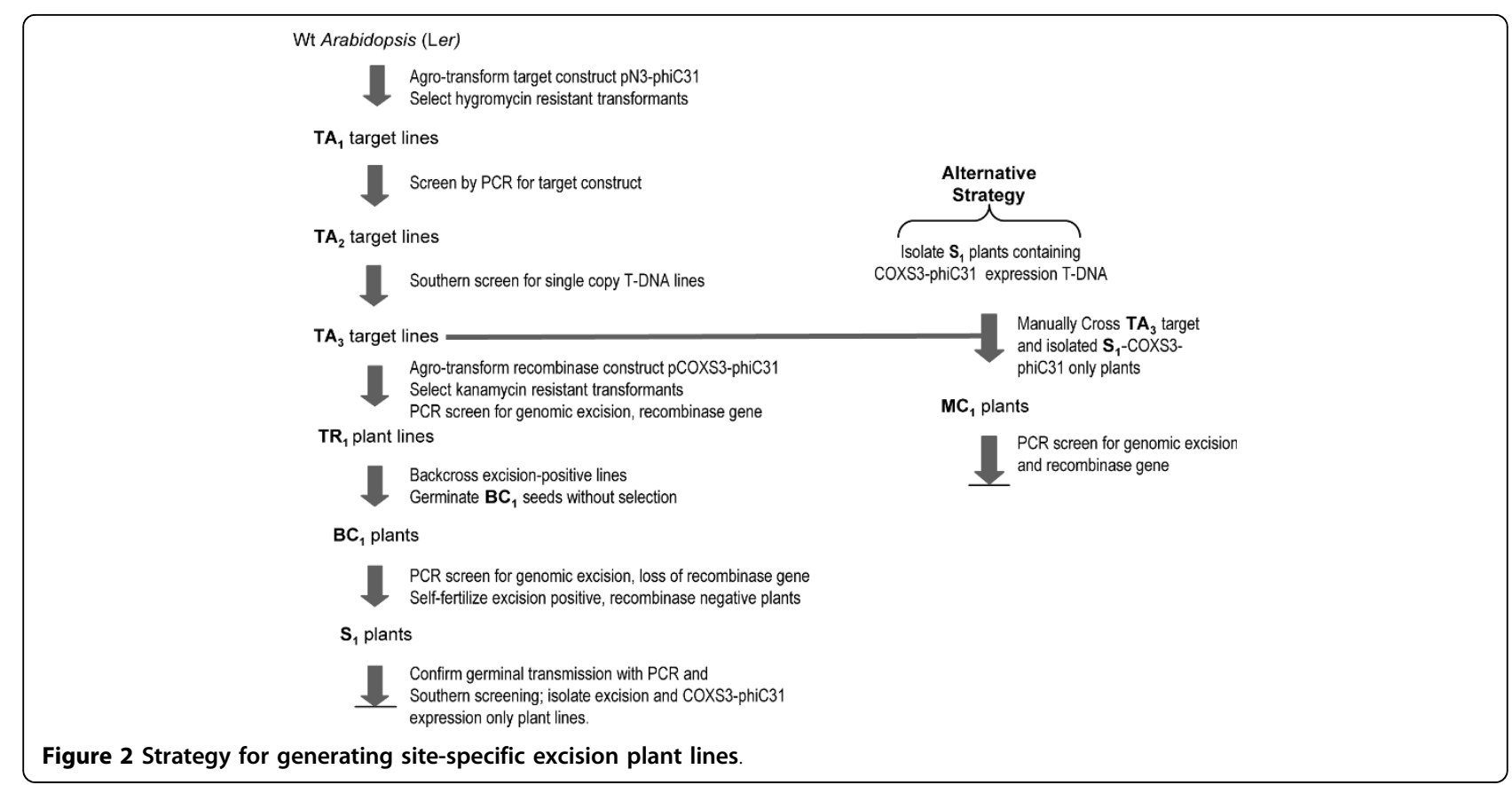

activity. Initially we attributed this reduced activity to lower levels of phiC31-mediated excision, but PCR analysis of lines where GUS activity was weak or undetectable were positive for excision of the target DNA. Given that the screening for GUS activity was not a reliable indicator of phiC31 site-specific recombination, we subsequently utilized PCR to screen for site-specific excision.

With the 65 TR1-phiC31.22, $31 \mathrm{TR}_{1}$-phiC31.31 and 19 $\mathrm{TR}_{1}$-phiC31.34 individuals, PCR with primers $\boldsymbol{e}$ and $\boldsymbol{f}$ (Fig. 1c) detected a $0.44 \mathrm{~kb}$ product expected for sitespecific excision (Fig. 3a). However, the $1.26 \mathrm{~kb}$ product representing the parental configuration was also detected in some individuals, which indicates the presence of unexcised target DNA. As each individual harbors an independent COXS3-phiC31 T-DNA integration at a different genomic location, with perhaps a different copy number or structural arrangements, the incomplete excision in some individuals may be due to variability in recombinase gene expression.

\section{Removal of the phiC 31 gene by segregation}

To determine if the genomic excision event occurred in the germline tissue, we examined whether the excised target was heritably transmitted to the progeny lacking the phiC31 gene. This analysis further resolved whether or not the excision reaction was generated de novo in each generation. We chose 5 individuals (Table 2) from each of the $\mathrm{TR}_{1}$-phiC31.22, $\mathrm{TR}_{1}$-phiC31.31 and $\mathrm{TR}_{1}$ phiC31.34 families to pollinate wild type recipients. The backcross progenies $\left(\mathrm{BC}_{1}\right)$ were grown without selection and then screened by PCR for the target locus (primers $\boldsymbol{e}$ and $\boldsymbol{f}$ ) and the recombinase gene (primers $\boldsymbol{g}$ and $\boldsymbol{h}$ ), which reveals whether excision occurred $(0.44 \mathrm{~kb}$ band) or not (1.26 kb band) and if phiC31 was present or absent (Fig. 3c, d). With the $\mathrm{TR}_{1}$-phiC31.22, TR - $^{-}$ phiC31.31 and $\mathrm{TR}_{1}$-phiC31.34, 59\% (115 of 194), 78\% (178 of 227) and $55 \%$ (118 of 214) of the $\mathrm{BC}_{1}$ plants harbored the target DNA, respectively.

For the five $\mathrm{TR}_{1}$-phiC31.22 plants that were backcrossed, $93 \%$ of the plants (107 of 115) that harbor the target locus showed excision of the attB and attPflanked DNA, with $48 \%$ (51 of 107) lacking the recombinase gene (Table 2). Of the $\mathrm{TR}_{1}$-phiC31.31 plants, $80 \%$ (142 of 178) of target plants showed excision of the attB and attP-flanked target, and 43\% (61 of 142) lack the recombinase gene (Table 2). A total of $87 \%$ of the $\mathrm{TR}_{1}$ phiC31.34 plants (103 of 118) harbored the target locus with excision of the attB and attP-flanked DNA, 1\% (1 of 103) lacked the recombinase gene (Table 2). The genomic excision $0.44 \mathrm{~kb}$ PCR product from two representative individuals from each family was sequenced and examined for conservative recombination. All of the phiC31-mediated excision PCR products sequenced were conservative and site specific (GenBank accession No. GU564447, Fig. 1e).

\section{$\mathrm{BC}_{1}$ progeny for molecular confirmation}

$\mathrm{BC}_{1}$ plants that showed excision but lacked the recombinase gene were self-fertilized to yield progeny designated $\mathrm{S}_{1}$-phiC31. PCR analysis on these plants again confirmed excision in the absence of the phiC31 


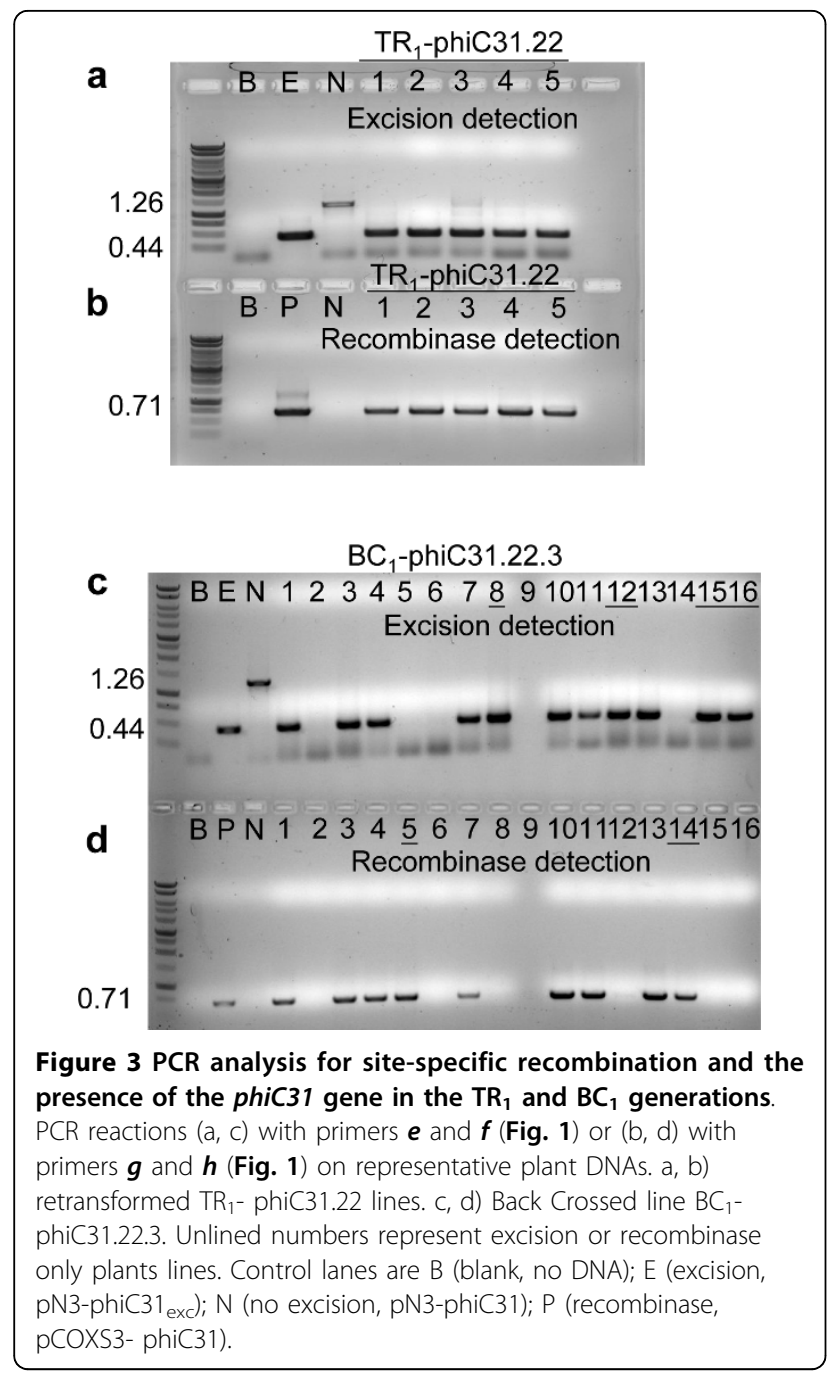

recombinase gene (Fig. 4a, b), which indicates germinal transmission of the excision event. For further confirmation, Southern blot hybridization was conducted on some of these $S_{1}$ individuals. The genomic DNA was isolated and cleaved with $E c o \mathrm{RV}$, which is expected to liberate either a $1.77 \mathrm{~kb}$ or a $0.96 \mathrm{~kb}$ fragment from the non-recombined or recombined structure, respectively (Fig. 1a, c). The GUS1350 probe detected the $1.77 \mathrm{~kb}$ band in the parental lines but not in the $S_{1}$ plants (Fig. $5 \mathrm{a}$, lanes 1-6). Instead, only the $0.96 \mathrm{~kb}$ band was observed for $S_{1}$ plants from the $\mathrm{TR}_{1}$-phiC31 lineage. Genomic DNA was also cleaved with XhoI, which should liberate a $0.88 \mathrm{~kb}$ fragment if the genome were to harbor a COXS3-phiC31 T-DNA. Hybridization with the NPT690 probe detected the nptII gene fragment in the parental controls but not in the $S_{1}$ plants determined to be excision positive and phiC31 negative (Fig. 5b, lanes 1-5) with the exception of a non-segregated $\mathrm{S}_{1}$-phiC31.34.9 plant line that contains both the excision product and the recombinase expression cassette (Fig. 5b, lane 6).

We further isolated, by segregation, phiC31 recombinase expression lines for the purpose of crossing to the original $\mathrm{TA}_{3}$ target lines to determine if a genomic excision event could be facilitated using this alternative approach (Fig. 2). Two independent lines from each of the three $\left(\mathrm{TR}_{1}\right.$-phiC31.22, 31 and 34$)$ secondary transformation events were isolated via PCR and designated lines $\mathrm{S}_{1}$-COXS3-22.3, 22.15; $\mathrm{S}_{1}$-COXS3-31.40, 31.83 and $\mathrm{S}_{1}$-COXS3-34.9, 34.20. Each of these six independently isolated lines has been crossed to the original target line $\mathrm{TA}_{3}$-phiC31.22. As the lines $\mathrm{S}_{1}$-COXS3-22.3 and $\mathrm{S}_{1}$-COXS3-22.15 were derived from the original $\mathrm{TR}_{1}$ phiC31.22 secondary transformation; crossing them back to the $\mathrm{TA}_{3}$-phiC31.22 target line was performed as a positive control for this line of investigation. The manually crossed progenies $\left(\mathrm{MC}_{1}\right)$ were grown without selection and screened by PCR for the target locus (primers $\boldsymbol{e}$ and $\boldsymbol{f}$ ) and the recombinase gene (primers $\boldsymbol{g}$ and $\boldsymbol{h}$; Fig. 6). Of the $\mathrm{MC}_{1}$-phiC31.22 plants that carried both the target locus and phiC31 gene, 61\% (19 of 31) of the tested individuals displayed the $0.44 \mathrm{~kb}$ excision band in the absence of the unexcised $1.26 \mathrm{~kb}$ target band when screened using PCR (Table 3; Fig. 6, lanes 1, 2). Of the $\mathrm{MC}_{1}$-phiC31.31 plants with both the target and phiC31, $100 \%$ (25 of 25 ) generated only the $0.44 \mathrm{~kb}$ excision PCR product (Table 3; Fig. 6, lanes 3, 4). While 92\% (34 of 37) of the $\mathrm{MC}_{1}$-phiC31.34 individuals generated only the $0.44 \mathrm{~kb}$ PCR product derived from an excised genomic target (Table 3; Fig. 6, lanes 5, 6).

Table 1 PCR analysis of $\mathrm{TR}_{1}$ plants

\begin{tabular}{|c|c|c|c|c|}
\hline TA Parent line & Plants tested & $\begin{array}{l}\text { Positive for recombinase } \\
\text { gene }^{a} \text { and target locus }\end{array}$ & Positive for excision $^{c}$ & $\begin{array}{l}\text { Positive for excision and negative } \\
\text { for unexcised product }\end{array}$ \\
\hline phiC31.22 & 88 & 65 & 47 & 35 \\
\hline phic31.31 & 67 & 31 & 21 & 14 \\
\hline phic31.34 & 43 & 19 & 17 & 2 \\
\hline \multicolumn{5}{|c|}{${ }^{a}$ Primers $g$ and $h$ yielded the $0.71 \mathrm{~kb}$ phiC31 fragment. } \\
\hline \multicolumn{5}{|c|}{${ }^{b}$ Primers $e$ and $f$ yielded the 1.26 and/or $0.44 \mathrm{~kb}$ fragment. } \\
\hline \multicolumn{5}{|c|}{${ }^{c}$ Primers $e$ and $f$ yielded the $0.44 \mathrm{~kb}$ excision fragment. } \\
\hline Primers $e$ and $f$ fail & detect a $1.26 \mathrm{~kb}$ & fragment. & & \\
\hline
\end{tabular}


Table 2 PCR analysis of $B C_{1}$ and $S_{1}$ plants

\begin{tabular}{|c|c|c|c|c|c|}
\hline $\mathrm{TR}_{1}$-Parent line & Plants tested & $\begin{array}{c}\text { Positive for } \\
\text { target locus }\end{array}$ & $\begin{array}{l}\text { Positive for } \\
\text { excision }{ }^{b}\end{array}$ & $\begin{array}{c}\text { Positive for excision and } \\
\text { negative for recombinase gene }\end{array}$ & $\begin{array}{l}\text { Positive for recombinase gene } \\
\text { and negative for target locus }{ }^{d}\end{array}$ \\
\hline phiC31.22.3 & 42 & 23 & 23 & 21 & 0 \\
\hline phiC31.22.15 & 17 & 16 & 16 & 2 & 0 \\
\hline phiC31.22.23 & 68 & 29 & 21 & 3 & 1 \\
\hline phiC31.22.29 & 61 & 44 & 44 & 24 & 1 \\
\hline phiC31.22.87 & 6 & 3 & 3 & 1 & 1 \\
\hline phiC31.31.1 & 59 & 55 & 28 & 14 & 1 \\
\hline phiC31.31.13 & 44 & 29 & 22 & 10 & 14 \\
\hline phiC31.31.23 & 14 & 8 & 8 & 2 & 4 \\
\hline phiC31.31.29 & 62 & 59 & 59 & 22 & 0 \\
\hline phiC31.31.36 & 48 & 27 & 25 & 13 & 5 \\
\hline phiC31.34.2 & 43 & 18 & 18 & 1 & 0 \\
\hline phiC31.34.5 & 44 & 23 & 8 & 0 & 2 \\
\hline phiC31.34.9 & 44 & 13 & 13 & 0 & 9 \\
\hline phiC31.34.20 & 42 & 26 & 26 & 0 & 1 \\
\hline phic31.34.24 & 41 & 38 & 38 & 0 & 0 \\
\hline
\end{tabular}

\section{Discussion}

Our interest in site-specific recombination lies in its ability to facilitate crop improvement through controlled engineering of the plant genome. Recently transgenic corn has been deregulated for the production of high lysine, a consumer directed product [22,23]. Further, this transgenic crop was engineered with the assistance of the site-specific recombinase technology for marker removal. Deregulation in this case required extensive studies to ensure that the recombinase mediated excision event was heritably transmitted to subsequent generations in the absence of the recombinase gene [23]. Such agricultural requirements, while obviously necessary, have elicited few detailed studies on the transmission of recombined chromosome transmission to progeny plants. The recombinase systems Cre/lox, Flp/ $F R T, \mathrm{R} / R S, \beta /$ six and $\operatorname{Par} \mathrm{A} / M R S$ have all been shown capable of germinal transmission in planta [19,24-30]. Therefore, our research investigated the publicly available phiC31 recombination system as a potential tool for the precise removal of plant transgenes. In order to demonstrate its utility for crop genome engineering and increase public acceptance of transgenic technology, the potential for predefined nuclear excision events and their germinal transmission was investigated. An advantage of phiC31 over existing recombinase systems is its unidirectional recombination activity, which prevents the re-insertion of the excision product into the genome. In addition, phiC31 has the ability to site-specifically integrate DNA into the host genome $[8,13]$ making this a versatile enzyme.

Our strategy began with the assumption that we could use gusA expression as a reporter for site-specific recombination. The pattern of GUS enzyme activity would reveal genomic excision of the target sequence and any tissue specificity in recombination. This strategy, however, failed to perform as expected with initial excised plants being either weak or completely devoid of GUS activity. Subsequent analysis of the original $\mathrm{TR}_{1}$ phiC31 progeny confirmed that use of reporter enzyme activity was an unreliable indicator of excision. We had also observed this phenomenon with other constructs used in both Arabidopsis and S. pombe $[8,19]$. It is possible that the $54 \mathrm{bp} a t t B / P$ hybrid sequence present within the transcript leader sequence of the gus $A$ gene may cause poor expression due to methylation or by some other mechanism that inhibits gene expression. Due to this circumstance, the analysis and scoring of site-specific excision was performed using PCR.

Site-specific excision was detected in all $\mathrm{TR}_{1}$ phiC31.22, $\mathrm{TR}_{1}$-phiC31.31 and $\mathrm{TR}_{1}$-phiC31.34 plants. The majority (72\%) of the $\mathrm{TR}_{1}$-phiC31.22 and $\mathrm{TR}_{1}$ phiC31.31 plants that demonstrated the presence of the excision product did not yield the PCR amplified 


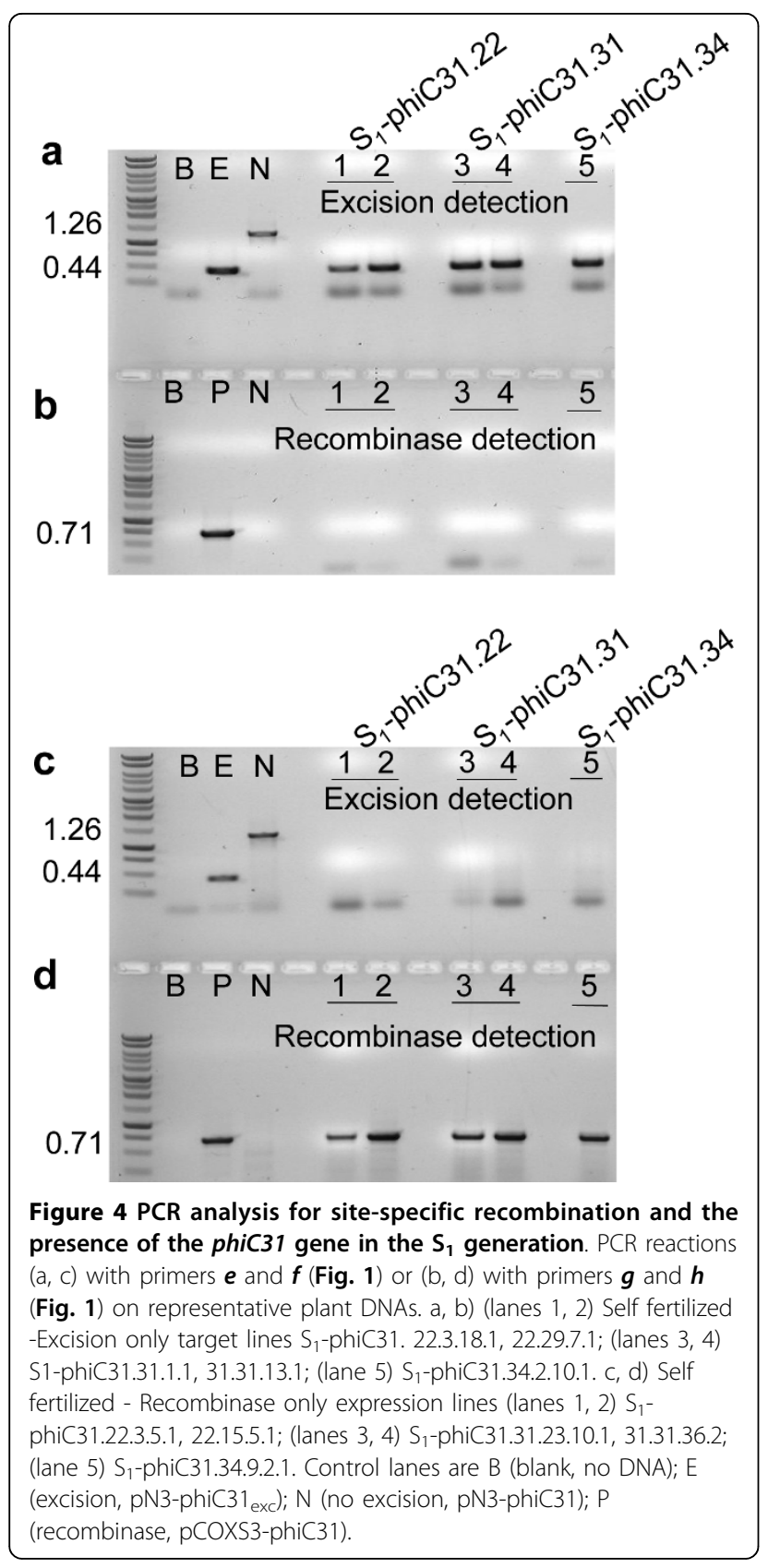

unexcised target band. This indicates that the phiC31mediated genomic excision reaction was complete, or nearly so, within many of these $\mathrm{TR}_{1}$ plants. The exception was line $\mathrm{TR}_{1}$-phiC31.34. Only $12 \%$ of the $\mathrm{TR}_{1}$ phiC31.34 plants were positive for the $0.44 \mathrm{~kb}$ excision band in the absence of the $1.26 \mathrm{~kb}$ unexcised target band. This may be due to unfavorable placement of the target construct within the Arabidopsis genome. Indeed, although the TR-phiC31.34 lines generated lower levels of recombinase-mediated excision than either the TRphiC31.22 or TR-phiC31.31 lines, when segregants (derived from TR-phiC31.34) containing only the

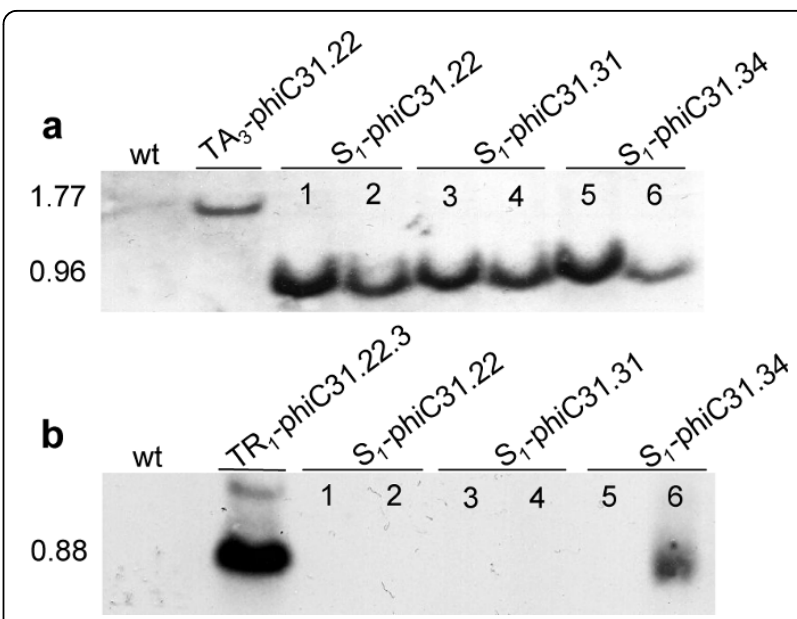

Figure $5 \mathrm{~S}_{1}$ plants examined by Southern blot analysis for excision and segregation of phic31 gene. a) Genomic DNA cleaved with EcoRV hybridized with a ${ }^{32}$ P-labeled GUS1350 probe (Fig. 1). b) Genomic DNA digested with Xhol and hybridized with a ${ }^{32}$ P-labeled NPT690 probe. Plant lines (lanes 1, 2) S1-phiC31.22.3.18.1, 22.29.7.1; (lanes 3, 4) $\mathrm{S}_{1}$ - phiC31.31.31.1.1, 31.31.13.1; (lane 5, 6) $\mathrm{S}_{1}$ phiC31.34.2.10.1; 34.9.20.1. Control lanes are wt (wild type Arabidopsis genomic DNA), $\mathrm{TA}_{3}$-phiC31.22, (target lines), $\mathrm{TR}_{1}{ }^{-}$ phiC31.22.23 (phiC31 recombinase expression line).

phiC31 expression cassette were manually crossed with TA-phiC31.22 target plants, 92\% of the progeny generated only the $0.44 \mathrm{~kb}$ excised target PCR product. This indicates that phiC31 functions well in these plants, despite performing less efficiently on the TA-phiC31.34 target. The simplest explanation is that the TA-phiC31.34 genomic location or structure was unfavorable to recombination in the germinal tissue.

From analysis of the $\mathrm{BC}_{1}$ plants, $85.6 \%$ (352 of 411) of those derived from the three $\mathrm{TR}_{1}$-phiC31 lines showed excision, while in a previous line of research $77.3 \%$ and $99.6 \%$ of the $\mathrm{BC}_{1}$ plants of the $\mathrm{TR}_{1}-\mathrm{Par} \mathrm{A}$ and $\mathrm{TR}_{1}-\mathrm{Cre}$ lines exhibited excision, respectively [19]. By this measure, it appears that the phiC31 recombinase mediated excision efficiency is more effective than ParA and approaching that of the Cre-lox system. Although, the majority of the $\mathrm{BC}_{1}$ lines displayed excised genomic target, it is difficult to give a precise quantitative assessment of the phiC31 activity since only a modest number of different target locations were thoroughly characterized. Variability in copy number and chromosome locations of the phiC31 gene can affect the amount of recombinase protein produced and thus impact the efficiency of the excision reaction observed, making a direct comparison difficult. Other excision strategies for the phiC31 recombinase are being investigated. These include the use of inducible or tissue specific promoters for controllable expression [31] use of self-deleting designs [32] and use of viral inoculation or 
Table 3 PCR analysis of $M_{1}$ plants

\begin{tabular}{lccccc}
\hline $\begin{array}{l}\text { MC }_{1} \text {-Parent } \\
\text { line }\end{array}$ & $\begin{array}{c}\text { Plants } \\
\text { tested }\end{array}$ & $\begin{array}{c}\text { Positive for target } \\
\text { locus }{ }^{a}\end{array}$ & $\begin{array}{c}\text { Positive for } \\
\text { recombinase gene }\end{array}$ & $\begin{array}{c}\text { Positive for excision and } \\
\text { recombinase gene }{ }^{c}\end{array}$ & $\begin{array}{c}\text { Positive for excision and negative for } \\
\text { unexcised product }^{d}\end{array}$ \\
\hline phiC31.22.3 & 11 & 10 & 11 & 8 & 8 \\
\hline phiC31.22.15 & 34 & 31 & 32 & 23 & 11 \\
\hline
\end{tabular}

\begin{tabular}{llllll}
\hline phiC31.31.40 & 17 & 16 & 16 & 8 & 8 \\
\hline phiC31.31.83 & 17 & 17 & 17 & 17 & 17 \\
\hline
\end{tabular}

\begin{tabular}{llllll}
\hline phiC31.34.9 & 68 & 44 & 23 & 15 & 15 \\
\hline phiC31.34.20 & 44 & 33 & 40 & 22 & 19 \\
\hline
\end{tabular}

${ }^{a}$ Primers $e$ and $f$ yielded the 1.26 and/or $0.44 \mathrm{~kb}$ target fragment.

${ }^{b}$ Primers $g$ and $h$ failed to detect the $0.71 \mathrm{~kb}$ phic 31 fragment.

c Primers $e$ and $f$ yielded the $0.44 \mathrm{~kb}$ excision fragment and primers $g$ and $h$ detect the $0.71 \mathrm{~kb}$ phiC31 fragment.

${ }^{d}$ Primers $e$ and $f$ yielded the $0.44 \mathrm{~kb}$ excision fragment and failed to detect a $1.26 \mathrm{~kb}$ target fragment.

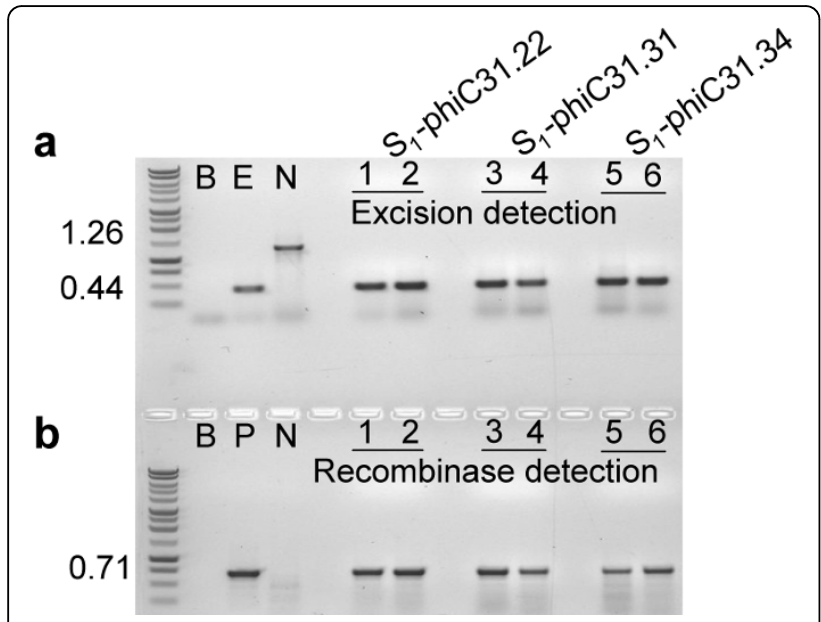

Figure 6 PCR analysis for site-specific recombination and the presence of the phiC31 gene in the $M_{1}$ generation. a) $P C R$ reactions with primers $\boldsymbol{e}$ and $\boldsymbol{f}$ (Fig. 1) or b) with primers $\boldsymbol{g}$ and $\boldsymbol{h}$ (Fig. 1) on manually crossed lines; (lanes 1, 2) MC 1 -phiC31.22.3, 22.15; (lanes 3, 4) $M C_{1}$-phiC31.31.40, 31.83; (lane 5, 6) $\mathrm{MC}_{1^{-}}$ phiC31.34.9, 34.20. Control lanes are B (blank, no DNA); E (excision, pN3-phiC31 exc); N (no excision, pN3-phiC31); P (recombinase, pCOXS3-phiC31).

Agrobacterium-infiltration for immediate but transient expression [33,34].

As an alternative method of recombinase introduction into the plant target lines, our lab tested hand pollination between phiC31 recombinase expressing plants and pN3phiC31 target plants. PCR analysis of the manually crossed $\mathrm{MC}_{1}$ progeny demonstrated that this is a viable method for the generation of individuals with genomic target excision (Fig. 6). However, it was observed that like secondary Agrobacterium transformation with the recombinase expression cassette, the genomic excision results varied between lines (Table 3). Use of a demonstrated recombinase expression line such as phiC31.31.83
(Table 3) enabled sufficient recombinase mediated excision events to fully excise all target DNA when crossed together. It was also observed that segregation of the secondary Agrobacterium transformed $\mathrm{TR}_{1}$ lines, without benefit of backcrossing, produced excised target and recombinase expression-only $\mathrm{T}$-DNA lines in the $\mathrm{TR}_{2}$ and $\mathrm{TR}_{3}$ generations (data not shown). This indicates that the phiC31 expression T-DNA in these lines was at a single locus or a low number of loci within the genome and that expression was sufficient to facilitate recombination allowing segregation by self- pollination.

Since PCR assays of genomic DNA from leaf tissue only indicates that excision has occurred in somatic cells, we utilized Southern blot analysis to ascertain whether target sequence removal had occurred in the germline. As long as phiC31 DNA was present in the genome, or the phiC31 protein was present in the germline cells, the possibility that recombination was generated de novo could not be ruled out. Hence, $\mathrm{BC}_{1}$ plants were screened by PCR for the absence of the phiC31 recombinase gene, and the following generation $\left(S_{1}\right.$ plants) was confirmed by Southern blot hybridization. As is clearly shown in Fig. 5 lanes \#1 - 5, germinal transmission of the genomic excision event in the absence of the phiC31 recombinase gene occurred, illustrating that the production of stable lines with the unwanted DNA removed can be achieved.

Controlled targeted integration with recombinase technology allows the application of more sophisticated recombinase strategies [35]. This technology enables the production of precisely engineered transgenic plants through genome specific transgene integration and has been reported to function in Arabidopsis, tobacco and rice [5,36-44] with Cre, Flp and R recombinase systems. The phiC31 recombinase with its uni-directional catalytic activity presents a novel way to facilitate stable sitespecific integration events without the elaborate 
strategies required by the bi-directional systems. Peerreviewed literature reported that phiC31 is capable of mammalian genome targeting $[45,46]$ and targeted integration into the plastid genome of tobacco [13]. Utilization of phiC31 for genome modification has been facilitated in mammalian species through the identification of cryptic attB or attP sites as potential locations for transgene introduction [46]. To this end our lab investigated, in silico, the presence of sequences similar to the phiC31 att sites within the Arabidopsis thaliana genome. We used a BLASTn search to investigate whether the Arabidopsis genome contains sequences similar to the minimal $34 \mathrm{bp}$ attB and $39 \mathrm{bp}$ attP sites [12]. The genomic sequences with the highest similarity to the att sites exhibited $>60 \%$ overall nucleotide identity. A total of seven sequences had 21-23 (61.8-67.7\%) of the 34 nucleotides conserved with the minimal attB sequence, while 14 native sequences had 24-27 (61.5$69.2 \%)$ nucleotides in common with the $39 \mathrm{bp}$ attP sequence (Fig. 7). While most of the sequences including the best matches for attP did contain the conserved core domain presumably essential for phiC31-mediated recombination, only three of the attB-like sequences contained the core sequence (Fig. 1d; Fig. 7). It is possible that some of these att-like sequences could potentially be used as a native target site for phiC31 mediated integration in Arabidopsis. Pseudo phiC31 attP sequences in the mouse, bovine and human genomes have been reported and some of them have been shown suitable for integration of introduced DNA [47-49].

Although unlikely, the potential for genomic excision, inversion and translocation mediated by these cryptic att sequences in Arabidopsis is possible. For excision, Arabidopsis chromosomes 3 and 5 carry both attB and attP-like sequences in direct orientation (Fig. 7). The closest correctly oriented sites are located $>500 \mathrm{~kb}$ apart on chromosome 3, but the cryptic attB does not contain a conserved core domain. Although it is theoretically possible that genomic recombination could occur via endogenous att-like sequences, the OXS3 promoterphiC31 plants did not exhibit compromised viability, morphological or growth defects. This differs from earlier observations using a 35S-phiC31 construct where Arabidopsis plants with crinkled leaves were common [C. Day and D.W. Ow, unpublished data]. Hence, this underscores the importance in controlling expression of the recombinase gene through appropriate use of promoters.

\section{Conclusion}

The purpose of the research was to provide proof-ofconcept that the phiC31 recombinase can mediate sitespecific genome modification in the plant germline tissue without affecting fecundity. The research established that the excision event was passed to subsequent generations in the absence of phiC31 and that the excision of $a t t B$ and $a t t P$-flanked DNA from the plant genome was a conservative site-specific event. In a majority of the phiC31 lines examined (11 out of 15), at least one $\mathrm{BC}_{1}$ segregant was recovered that contained a germinally transmitted excision event lacking the phiC31 gene. These results were validated with Southern blot hybridization and demonstrate that the secondary transformation strategy used in this study is feasible for the production of marker-free transgenic plants. This approach may prove particularly useful in those species where cross pollination is not possible or undesirable. We further demonstrate that an alternative approach to marker removal where the recombinase is introduced into the excision test target plants with cross pollination is also a viable strategy. Molecular analysis confirmed that the genomic excision was site-specific and conservative. Therefore, taken together the results clearly establish that the phiC31 system performs genomic excision, generating stable transgenic recombinase-free Arabidopsis plants with unwanted DNA removed.

\section{Methods \\ DNA constructs}

pN3-phiC31 (GenBank accession No. GU564446), (Fig. 1a): An NheI-attB-stuffer-attP-AscI fragment was retrieved from pPB-phiC31 [8] and inserted into binary vector pCambia-1301 http://www.cambia.org/daisy/cambia in which the NcoI site between $35 S$ and gusA had been changed to SpeI and $A s c$ I. The vector contains hptII (hygromycin phosphotransferase II) for selection in plants outside the region of site-specific excision to allow for progeny tracking. The pN3-phiC31 exc vector for control lanes (Fig. 3, 4 and 6, lane E) was generated by removal of the non-coding stuffer region by recombinase-mediated excision in bacteria.

pCOXS3-phiC31 (GenBank accession No. GU564445), (Fig. 1b): The phiC31 ORF was Phusion (NEB, New England Biolabs) PCR amplified with a 5' AscI and 3' SpeI sites (underlined) and inserted into pCOXS3-ParA [19] to generate the final construct. Primers used were 5'-AGTCGGCGCGCCATGACACAAGGGGTTGT GAC-3' and 5'-AGTCACTAGTCTACGCCGCTACGTCTTC-3'. The $1.5 \mathrm{~kb}$ fragment promoter of the OXS3 gene (AGI At5g56550) from Arabidopsis thaliana (ecotype: Ler) was used to express the phiC31 ORF, as previously described $[19,20]$. The pCAMBIA 2300 http://www.cambia.org/daisy/cambia, binary vector with nptII (neomycin phosphotransferase II) for plant selection was used as the backbone for plant transformation.

Agrobacterium tumefaciens GV3101 was used for transformation of Arabidopsis (ecotype: Ler) by the floral dip method [50] modified by adding $0.01 \%$ Silwet 


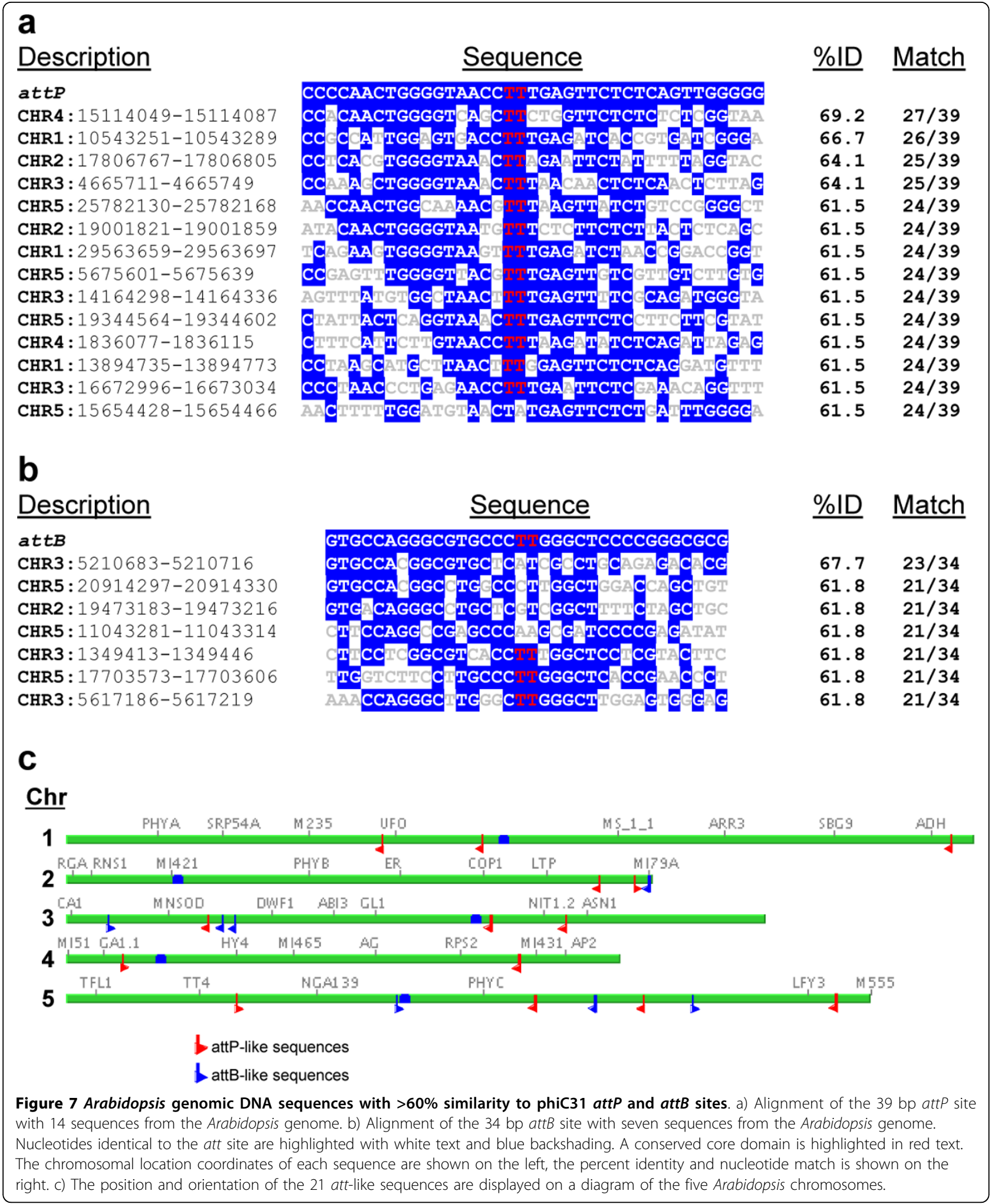


L-77 (Lehle Seeds, Round Rock, TX) to the infiltration medium. Primary transformants were selected on $1 \times$ MS medium (Sigma), 1\% sucrose, 0.7\% agar with $20 \mu \mathrm{g} /$ $\mathrm{ml}$ hygromycin or $50 \mu \mathrm{g} / \mathrm{ml}$ kanamycin as needed for 10 days prior to cultivation in soil.

\section{PCR analysis}

Genomic DNA was extracted by grinding a single leaf in $400 \mu \mathrm{l}$ of buffer $(200 \mathrm{mM}$ Tris $\mathrm{HCl} \mathrm{pH} \mathrm{7.8,250} \mathrm{mM}$ $\mathrm{NaCl}, 25 \mathrm{mM}$ EDTA, 0.5\% SDS). After centrifugation, the isopropanol precipitated pellet was washed with $70 \%$ ethanol and resuspended in $50 \mu \mathrm{l}$ of $\mathrm{H}_{2} \mathrm{O}$. Two $\mu \mathrm{l}$ of genomic DNA in $25 \mu \mathrm{l}$ volume was used per PCR reaction. Primers were (Fig. 1): $\boldsymbol{e}$ (5'-ATATCTCCACTGACGTAAGG-3'), $\boldsymbol{f}$ (5'-ATCATCATCATAGACACACG-3' for N3-phiC31); $\boldsymbol{g}$ (5'-AGTCGGCGCGCCATGACACAAGGGGTTGTGAC-3'), $\boldsymbol{h}$ (5'- GTGCGTCTTGATCTCACG-3' for phiC31). Gel images were digitized with a resolution of $200 \mathrm{dpi}$ in black on white background TIF format.

\section{Southern blot analysis}

Genomic DNA was extracted from plant aerial portions using a modified cetyl- trimethyl-ammonium bromide method as described [51]. The $0.79 \mathrm{~kb}$ GUS1350 and $0.69 \mathrm{~kb}$ NPT $690{ }^{32} \mathrm{P}$-labeled probes were produced by $\mathrm{Taq}^{\mathrm{TM}}$ polymerase (Promega) using primers 5'-CAAGACCCTTCCTCTATATAAG-3' and 5'-CGAGTTCATAGAGATAACCTTC-3' for GUS1350 and primers 5'GATTGAACAAGATGGATTGCACGC-3' and 5' - CCACAGTCGATGAATCCAGAAAAGC-3' for NPT690.

\section{Acknowledgements \\ We thank K. McCue and C. Tobias for reading the manuscript. We also express our thanks to Jamison Smith and Isaish Deresa for technical assistance. References to a company and/or product by the USDA are only for purposes of information and do not imply approval or recommendation of the product to the exclusion of others that may also be suitable. Research was funded by USDA-ARS project 5325-21000-002-00D. \\ Author details \\ ${ }^{1}$ Crop Improvement and Utilization Research Unit, Western Regional Research Center, USDA-ARS, 800 Buchanan Street, Albany CA, 94710, USA . ${ }^{2}$ Plant Gene Expression Center and UC Berkeley, 800 Buchanan Street, Albany CA, 94710, USA . ${ }^{3}$ Current address: South China Botanical Garden, Xingke Road 723, Tianhe, Guangzhou, China 510650.}

\section{Authors' contributions}

JT designed the approach, constructed the plasmids, collected data, interpreted the research results, drafted and edited the manuscript. JT supervised RC, prepared and submitted the manuscript. RC provided technical assistance with plant maintenance, DNA preparation, PCR data collection and analysis. Participated with manuscript preparation and editing. RT provided bioinformatics research on the cryptic attB and attP sites and performed Southern blot hybridization and analysis. Participated in the drafting and editing of the manuscript. YY provided assistance on background studies, data interpretation and manuscript editing. DO provided data interpretation and manuscript editing. All authors have read and approved the final manuscript.
Received: 25 November 2009

Accepted: 23 February 2010 Published: 23 February 2010

\section{References}

1. Herring RJ: Opposition to transgenic technologies: ideology, interests and collective action frames. Nat Rev Genet 2008, 9:458-63.

2. Cellini F, Chesson A, Colquhoun I, Constable A, Davies HV, Engel KH, Gatehouse AM, Karenlampi S, Kok EJ, Leguay JJ, Lehesranta S, Noteborn HP, Pedersen J, Smith M: Unintended effects and their detection in genetically modified crops. Food Chem Toxicol 2004, 42:1089-1125.

3. Hare PD, Chua NH: Excision of selectable marker genes from transgenic plants. Nat Biotechnol 2002, 20:575-80.

4. Hohn B, Levy AA, Puchta H: Elimination of selection markers from transgenic plants. Curr Opin Biotechnol 2001, 12:139-143.

5. Chawla R, Ariza-Nieto M, Wilson AJ, Moore SK, Srivastava V: Transgene expression produced by biolistic-mediated, site-specific gene integration is consistently inherited by the subsequent generations. Plant Biotechnol J 2006, 4:209-18.

6. Sauer B: Functional expression of the cre-lox site-specific recombination system in the yeast Saccharomyces cerevisiae. Mol Cell Biol 1987, 7(6):2087-2096.

7. Miki B, McHugh S: Selectable marker genes in transgenic plants: applications, alternatives and biosafety. J Biotechnology 2004, 107(3):193-232.

8. Thomson JG, OW DW: Site-specific recombination systems for the genetic manipulation of eukaryotic genomes. Genesis 2006, 44:465-476.

9. Keravala A, Groth AC, Jarrahian S, Thyagarajan B, Hoyt JJ, Kirby PJ, Calos MP: A diversity of serine phage integrases mediate site-specific recombination in mammalian cells. Mol Genet Genomics 2006, 276(2):135-146.

10. Thomason LC, Calendar R, Ow DW: Gene insertion and replacement in Schizosaccharomyces pombe mediated by the Streptomyces bacteriophage phiC31 site-specific recombination system. Mol Genet Genomics 2001, 265:1031-1038.

11. Thorpe HM, Smith MC: In vitro site-specific integration of bacteriophage DNA catalyzed by a recombinase of the resolvase/invertase family. Proc Natl Acad Sci USA 1998, 95(10):5505-5510.

12. Groth AC, Olivares EC, Thyagarajan B, Calos MP: A phage integrase directs efficient site-specific integration in human cells. Proc Natl Acad Sci USA 2000, 97(11):5995-6000.

13. Lutz K, Corneille S, Azhagiri AK, Svab Z, Maliga P: A novel approach to plastid transformation utilizes the phiC31 phage integrase. Plant J 2004, 37:906-913.

14. Kittiwongwattana $C$, Lutz K, Clark M, Maliga P: Plastid marker gene excision by the phiC31 phage site-specific recombinase. Plant Mol Biol 2007, 64:137-43.

15. Lutz KA, Maliga P: Plastid genomes in a regenerating tobacco shoot derive from a small number of copies selected through a stochastic process. Plant J 2008, 56:975-83.

16. Gils M, Marillonnet $S$, Werner $S$, Grützner R, Giritch A, Engler $C$, Schachschneider R, Klimyuk V, Gleba Y: A novel hybrid seed system for plants. Plant Biotechnol J 2008, 6(3):226-235.

17. Rubtsova M, Kempe K, Gils A, Ismagul A, Weyen J, Gils M: Expression of active Streptomyces phage phiC31 integrase in transgenic wheat plants. Plant Cell Rep 2008, 27:1821-1831.

18. Bayley CC, Morgan M, Dale EC, Ow DW: Exchange of gene activity in transgenic plants catalyzed by the Cre-lox site-specific recombination system. Plant Mol Biol 1992, 18:353-361.

19. Thomson JG, Yau YY, Blanvillain R, Chiniquy D, Thilmony R, Ow DW: ParA resolvase catalyzes site-specific excision of DNA from the Arabidopsis genome. Transgenic Res 2009, 18(2):237-48.

20. Blanvillain R, Kim JH, Lima A, Ow DW: OXIDATIVE STRESS 3 is a chromatinassociated factor involved in tolerance to heavy metals and oxidative stress. Plant J 2009, 57(4):654-665.

21. Laubinger $S$, Zeller G, Henz SR, Sachsenberg T, Widmer CK, Naouar N, Vuylsteke M, Schölkopf B, Rätsch G, Weigel D: At-TAX: a whole genome tiling array resource for developmental expression analysis and transcript identification in Arabidopsis thaliana. Genome Biol 2008, 9:R112.

22. Ow DW: GM maize from site-specific recombination technology, what next?. Curr Opin Biotechnol 2007, 18:115-120. 
23. Environmental USDA-APHIS: Assessment of Petition 04-229-01P. http:// www.aphis.usda.gov/brs/aphisdocs/04_22901p_pea.pdf.

24. Dale EC, Ow DW: Gene transfer with subsequent removal of the selection gene from the host genome. Proc Natl Acad Sci USA 1991, 88:10558-10562.

25. Russell SH, Hoopes JL, Odell JT: Directed excision of a transgene from the plant genome. Mol Gen Genet 1992, 234:49-59.

26. Srivastava V, Ow DW: Single-copy primary transformants of maize obtained through the co-introduction of a recombinase-expressing construct. Plant Mol Biol 2001, 46:561-566.

27. Lyznik LA, Rao KV, Hodges TK: FLP-mediated recombination of FRT sites in the maize genome. Nucleic Acids Res 1996, 24:3784-3789.

28. Hu Q, Kononowicz-Hodges $\mathrm{H}$, Nelson-Vasilchik K, Viola D, Zeng P, Liu H, Kausch AP, Chandlee JM, Hodges TK, Luo H: FLP recombinase-mediated site-specific recombination in rice. Plant Biotechnol J 2008, 6:176-188.

29. Grønlund JT, Stemmer C, Lichota J, Merkle T, Grasser KD: Functionality of the $\beta /$ six Site-Specific Recombination System in Tobacco and Arabidopsis: A Novel Tool for Genetic Engineering of Plant Genomes. Plant Mol Biol 2007, 63:545-556.

30. Nanto K, Ebinuma H: Marker-free site-specific integration plants. Transgenic Res 2008, 17:337-344.

31. Zuo J, Niu QW, Chua NH: Technical advance: An estrogen receptor-based transactivator XVE mediates highly inducible gene expression in transgenic plants. Plant J 2000, 24:265-273.

32. Hoff T, Schnorr KM, Mundy J: A recombinase-mediated transcriptional induction system in transgenic plants. Plant Mol Biol 2001, 45:41-49.

33. Jia $H$, Pang $Y$, Chen $X$, Fang R: Removal of the selectable marker gene from transgenic tobacco plants by expression of Cre recombinase from a tobacco mosaic virus vector through agroinfection. Transgenic Res 2006, 15:375-384.

34. Kopertekh L, Schiemann J: Agroinfiltration as a tool for transient expression of cre recombinase in vivo. Transgenic Res 2005, 14:793-798.

35. Ow DW: Site-Specific Recombination for Plant Genetic Engineering: Strategy for Agro-Mediated Gene Stacking. ISHS Acta Horticulturae 738 International Symposium on Biotechnology of Temperate Fruit Crops and Tropical Species: Mar31, 2007; The Netherlands, Drukkerij Jansen BV Litz RE, Scorza R 2007, 117-127.

36. Albert $H$, Dale EC, Lee $E$, Ow DW: Site-specific integration of DNA into wild-type and mutant lox sites placed in the plant genome. Plant J 1995, 7:649-659.

37. Choi S, Begum D, Koshinsky H, Ow DW, Wing RA: A new approach for the identification and cloning of genes: the pBACwich system using Cre/lox site-specific recombination. Nucleic Acids Res 2000, 28:E19.

38. Day CD, Lee E, Kobayashi J, Holappa LD, Albert H, Ow DW: Transgene integration into the same chromosome location can produce alleles that express at a predictable level, or alleles that are differentially silenced. Genes Dev 2000, 14:2869-2880.

39. Nanto K, Yamada-Watanabe K, Ebinuma H: Agrobacterium -mediated RMCE approach for gene replacement. Plant Biotechnol I 2005, 3:203-214.

40. Nanto K, Ebinuma H: Marker-free site-specific integration plants. Transgenic Res 2008, 17:337-344.

41. Srivastava V, Ow DW: Biolistic mediated site-specific integration in rice. Molecular Breeding 2002, 8:345-350.

42. Srivastava V, Ariza-Nieto M, Wilson AJ: Cre-mediated site-specific gene integration for consistent transgene expression in rice. Plant Biotech J 2004, 2:169-179.

43. Vergunst AC, Hooykaas PJ: Cre/lox-mediated site-specific integration of Agrobacterium T-DNA in Arabidopsis thaliana by transient expression of cre. Plant Mol Biol 1998, 38:393-406.

44. Vergunst AC, Jansen LE, Hooykaas PJ: Site-specific integration of Agrobacterium T-DNA in Arabidopsis thaliana mediated by Cre recombinase. Nucleic Acids Res 1998, 26:2729-2734.

45. Belteki G, Gertsenstein M, Ow DW, Nagy A: Site-specific cassette exchange and germline transmission with mouse ES cells expressing phiC31 integrase. Nat Biotechnol 2003, 21:321-324.

46. Thyagarajan B, Olivares EC, Hollis RP, Ginsburg DS, Calos MP: Site-specific genomic integration in mammalian cells mediated by phage phiC31 integrase. Mol Cell Biol 2001, 21(12):3926-3934.

47. Thyagarajan B, Guimarães MJ, Groth AC, Calos MP: Mammalian genomes contain active recombinase recognition sites. Gene 2000, 244(1-2):47-54.
48. Chalberg TW, Portlock JL, Olivarer EC, Thyagarajan B, Kirby PJ, Hillman RT, Hoelters J, Calos MP: Integration specificity of phage phiC31 integrase in the human genome. J Mol Bio 2006, 357:28-48.

49. Ou HL, Huang Y, Qu LJ, Xu M, Yan JB, Ren ZR, Huang SZ, Zeng YT: A phiC31 integrase-mediated hotspot in favor of transgene expression exists in bovine genome. FEBS $J$ 2009, 276:155-63.

50. Clough SJ, Bent AF: Floral dip: a simplified method for Agrobacterium mediated transformation of Arabidopsis thaliana. Plant $J$ 1998, 16:735-743.

51. Sambrook J, Russell DW: Southern Blot Hybridization. Molecular Cloning A Laboratory Manual NewYork: Cold Spring Harbor PressArgentine J , 3 2001, 6.33-6.46.

doi:10.1186/1472-6750-10-17

Cite this article as: Thomson et al: PhiC31 recombination system demonstrates heritable germinal transmission of site-specific excision from the Arabidopsis genome. BMC Biotechnology 2010 10:17.

\section{Submit your next manuscript to BioMed Central and take full advantage of:}

- Convenient online submission

- Thorough peer review

- No space constraints or color figure charges

- Immediate publication on acceptance

- Inclusion in PubMed, CAS, Scopus and Google Scholar

- Research which is freely available for redistribution

Submit your manuscript at www.biomedcentral.com/submit
Ciomed Central 